\title{
África no feminino: As mulheres portuguesas e a Guerra Colonial
}

Africa in the feminine: Portuguese women and the Colonial War

L'Afrique au féminin : les femmes portugaises et la Guerre Coloniale

\section{Margarida Calafate Ribeiro}

\section{OpenEdition}

\section{Journals}

\section{Edição electrónica}

URL: http://journals.openedition.org/rccs/1076

DOI: $10.4000 /$ rccs. 1076

ISSN: 2182-7435

\section{Editora}

Centro de Estudos Sociais da Universidade de Coimbra

\section{Edição impressa}

Data de publição: 1 Junho 2004

Paginação: 07-29

ISSN: 0254-1106

\section{Refêrencia eletrónica}

Margarida Calafate Ribeiro, "África no feminino: As mulheres portuguesas e a Guerra Colonial », Revista Crítica de Ciências Sociais [Online], 68 | 2004, colocado online no dia 01 outubro 2012, criado a 01 maio 2019. URL : http://journals.openedition.org/rccs/1076 ; DOI : 10.4000/rccs.1076 


\section{África no feminino: As mulheres portuguesas e a Guerra Colonial ${ }^{1}$}

Procura-se traçar as linhas gerais que no discurso crítico histórico, político, sociológico e literário levaram a considerar a guerra como um fenómeno não exclusivamente masculino. Dentro da situação portuguesa, visa-se interpretar o "papel de apoio" que sempre esteve reservado às mulheres, de um ponto de vista público e privado, e analisar com mais detalhe a situação das mulheres portuguesas que acompanharam os maridos em missão militar em África, durante o período da Guerra Colonial.

Talvez só rivalizando com o amor ou tantas vezes magnificamente combinada com ele, a guerra tem sido, ao longo da história, tema de inspiração para os grandes escritores de todos os tempos. Cronistas gregos, romanos e hebreus, épicos e dramaturgos, foram repetidamente inspirados pela guerra e pelos ideais a ela ligados para escreverem aquelas que haviam de ser algumas das grandes obras de referência da civilização judaico-cristã. Também no grande corpus de literatura europeia de sagas medievais e épicas a guerra foi sendo um tema central, ligando-se a ela ideais de identidade e grandeza nacionais, de heroicidade e de um imaginário religioso ligado à afirmação do ideal de Cruzada de conquista do mundo para Cristo. Com a Renascença e o alargamento do mundo que os Descobrimentos trouxeram, os movimentos de conquista das novas terras foram acentuando os ideais político-religiosos já amplamente desenhados na Idade Média. Camões, o grande poeta do amor, mas também "o grande cultor de batalhas" ${ }^{2}$, narra em Os Lusíadas

\footnotetext{
${ }^{1}$ Gostaria de agradecer aos directores e funcionários do Arquivo Histórico Militar, do Arquivo Geral do Exército, do Arquivo Histórico da Força Aérea e do Arquivo do Ministério da Educação pela generosidade e eficiência de que deram provas, pelos conhecimentos que me transmitiram e que tornaram possível a recolha de grande parte da informação referida ao longo deste artigo. Relativamente ao material fotográfico, gostaria de agradecer ao coordenador do Arquivo de Fotografia de Lisboa, Dr. Fernando Costa, pela generosidade e rigor de todas as indicações que me deu, e à Senhora Dona Rosa Nogueira, que me facultou algumas das suas fotografias dos tempos em que viveu em Moçambique acompanhando o marido em missão militar durante o período da Guerra Colonial.

2 Belisário Pimenta, apud Bebiano, 1993: 75.
} 
a acção de conquista dos navegantes portugueses, integrando-a num movimento mundial de Cruzada e segundo um modelo ficcional que realça a vertente heróica dos factos que refere (Bebiano, 1993: 75) e o valor profético da missão. Recordemos que Os Lusíadas são dedicados ao jovem rei D. Sebastião, amante de Deus e das armas e que, numa tentativa já então anacrónica de purificação e glória do seu reino, lança o país na malograda jornada de Alcácer-Quibir, onde Portugal perderia o seu rei, a sua armada, a sua nobreza, a sua posição mundial e em breve a sua independência. ${ }^{3}$ Havia aqui falhado a harmonia da conquista camoniana em que Marte se tornava amante de Vénus, para pelo amor regenerar o homem da guerra, como aconteceu na Ilha dos Amores, ou, no contexto da viagem marítima, libertar os homens dos perigos do mar. Recordemos no Canto VI de Os Lusíadas, o episódio dos ventos fortes que os navegantes desesperadamente enfrentavam até que Vénus enviou as ninfas para pelo amor seduzirem os ventos e acalmá-los, libertando assim os navegantes; recordemos o episódio da Ilha dos Amores (Canto IX), símbolo da recompensa dos guerreiros pelos perigos passados e de regeneração da violência humana que a guerra e a conquista importam pela via do amor ${ }^{4}$ ou ainda a doce Bárbara "cativa" de quem muitos foram ficando cativos.

Mas, de acordo com os historiadores, só com o advento do Romantismo, em que se afirma a valorização do "eu" e da sua perspectiva poética ou narrativa enquanto sujeito experienciador da história e do seu tempo, é que genericamente podemos considerar a existência de uma literatura de guerra no sentido moderno. Catherine Savage Brosman, no seu estudo sobre as funções de uma literatura de guerra considera que o que distingue a expressão literária que tem por objecto a guerra, pelo menos nos tempos modernos, é precisamente a ênfase narrativa colocada na dimensão vivencial de um sujeito individual, cuja experiência e testemunho literário o convertem

\footnotetext{
${ }^{3}$ Sobre a batalha de Alcácer-Quibir, ver Valensi, 1996.

${ }^{4}$ Cf. as seguintes estrofes do Canto VI de Os Lusíadas: "Mas já a amorosa Estrela cintilava/Diante do Sol claro, no horizonte,/Mensageira do dia, e visitava/A terra e o largo mar, com leda fronte. /A Deusa que nos Céus a governava,/De quem foge o ensífero Orionte,/Tanto que o mar e a cara armada vira,/Tocada junto foi de medo e de ira. [...]/Assi foi; porque, tanto que chegaram/À vista delas, logo lhe falecem/As forças com que dantes pelejaram,/E já como rendidos lhe obedecem; /Os pés e mãos parece que lhe ataram/Os cabelos que os raios escurecem./A Bórea, que do peito mais queria,/Assi disse a belíssima Oritia:/- Não creias, fero Bóreas, que te creio/Que me tiveste nunca amor constante,/Que brandura é de amor mais certo arreio/E não convém furor a firme amante./Se já não pões a tanta insânia freio,/não esperes de mim, daqui em diante,/Que possa mais amar-te, mas temer-te;/Que amor, contigo, em medo se converte./[...] Desta maneira as outras amansavam/Subitamente os outros amadores;/E logo à linda Vénus se entregavam,/Amansadas as iras e os furores./Ela lhe prometeu, vendo que amavam,/ Sempiterno favor em seus amores, /Nas belas mãos tomando-lhe homenagem/De lhe serem leais esta viagem." (Camões, 1992: 170/1 [Canto VI, estrofes 84; 88; 89 e 91]). Cf. Macedo, 1998.
} 
em sujeito histórico (Brosman, 1992: 85). Mas foi sobretudo após a experiência dilacerante da Primeira Guerra Mundial que na narração se verificou o deslocamento da focalização de um colectivo ou individual, mormente heróico e moralizante pela sua agressividade guerreira, para um eu em ruptura espacial e temporal pela experiência do conflito, o que acusava a transferência de um discurso de celebração nacional para um campo semântico de interrogações, responsabilidades, valores morais, sentimentos e identidades individuais. Como claramente mostra a célebre "Declaration of Defiance" do poeta inglês Siegfried Sassoon, não era só a imensidão do poderio tecnológico que invadia e desclassificava o individual nesta guerra, que aqui era posto em causa, mas todo um conjunto de valores que com esta guerra se desmoronava. Era a denúncia em letra de forma do que o malogrado poeta Wilfred Owen designou como "The old Lie: Dulce et decorum est /Pro patria mori" (Owen, 1983: 140) e que é, na verdade, a "velha mentira" de todas as guerras. Com estes textos, inscrevia-se para sempre na literatura ocidental o sofrimento dos soldados e a sua coragem, os seus medos e a sua desorientação num mundo desfeito pelo absurdo da guerra. E, de facto, basta pensarmos na poesia destes poetas ingleses da Primeira Guerra, no estudo de John Keegan, The Face of the Battle, onde o desejo de combater é denunciado como um fenómeno incerto para muitos homens, no corpus poético analisado por Paul Fussell em The Great War and Modern Memory (Fussell, 1975), ou ainda nos textos dos franceses Henri Barbusse, Roland Dorgelès ou no nosso Jaime Cortesão, em Memórias da Grande Guerra $(1919)^{5}$ para perceber que a memória da experiência bélica, o valor político a ela inerente e a sua expressão literária apontavam para a mudança.

A crise de masculinidade que esta onda literária, historiográfica e ensaística denunciava, bem como o discurso da psiquiatria relativo ao reconhecimento da neurose de guerra, abriram caminho para que se começasse a pensar a guerra como um fenómeno não exclusivamente masculino, ou melhor, para se começar a pensar que algumas representações tradicionais de feminilidade ${ }^{6}$ ajudariam a compreender a experiência masculina

\footnotetext{
${ }^{5}$ Cf. os seguintes passos de Jaime Cortesão: "Pálidos, magros, exaustos, os pulmões roídos dos gases, os pés triturados das marchas, sem esperança nem apoio moral, arrastam-se sob o imenso fogo que tomba do céu, por essas estradas, como uma legião miserável de abandonados."; "Nisto um silvo galopante vem de lá, rasa numa lufada horrível as nossas cabeças; um estampido cataclísmico, a terra, os sacos, a madeira, nós mesmos tudo dança projectado; depois uma chuva de pedras, torrões, detritos, cai do alto, bate no capacete, fustiga a carne, graniza à volta, com violência." (apud Dias, 1995: 431).

"Refiro-me ao reconhecimento da neurose de guerra ("shell shock"), no decorrer da Primeira Grande Guerra, em que as interpretações de histeria e outros comportamentos psicológicos tradicionalmente atribuídos às mulheres ajudaram a compreender o fenómeno. Cf. os escritos de W. H. Rivers, nomeadamente o seu texto inicial e polémico "The Repression of War Experience”, publi-
} 
da guerra, convertendo assim este fenómeno em algo em que o estudo das posições e percepções femininas se revelaria enriquecedor e, eventualmente, esclarecedor. Mais tarde, já nos anos 70, uma segunda vaga de historiadoras e feministas trouxe à discussão se as Grandes Guerras teriam sido apenas um empreendimento masculino (Higonnet et al., 1987: 3). Olhando para as periferias destas guerras, essas investigadoras encontraram as mulheres: em casa, na chamada "homefront", nas fábricas de munições, nas enfermarias dos hospitais militares, na resistência, nos serviços militares, nos locais de prostituição, vítimas de violações, e ainda, na propaganda institucional, ora estimulando os homens a marchar, ora apontadas como o símbolo a defender pelos homens na frente de guerra. E encontraram-nas também, e sobretudo, no pós-guerra, em que o próprio discurso de militarismo que alimenta a guerra, com a sua marca de masculinidade, protectora das "mulheres e crianças", como se dizia na propaganda, é substituído por um discurso integrador que contempla a relação entre homem e mulher como a base da sociedade de paz que se quer construir. É de facto nas mulheres que reside a garantia do regresso a uma certa normalidade, ainda que com as lutas e os custos inerentes à libertação, em termos sociais e laborais, que a situação de guerra lhes trouxe, com os homens fora dos seus habituais locais de trabalho. Por isso, o discurso do pós-guerra, ao mesmo tempo que reafirma as relações pré-existentes entre os dois sexos, num apelo ao tempo anterior à guerra objectivamente fantasiado num idealismo melancólico e retórico, reestrutura estas mesmas relações com vista à paz social, o que implica sempre, em termos femininos, um recuo relativamente às posições adquiridas durante a guerra, pois o pós-guerra não traz por si só a alteração das relações patriarcais que caracterizam as sociedades, levando à efectiva transformação. ${ }^{7}$ No entanto, nunca se volta ao ponto de partida. Ao deslocar a mulher das margens silenciosas onde se colocava para o centro da análise, ou melhor, para uma posição analítica da guerra como um fenómeno masculino e feminino, a história das Grandes Guerras ganhou uma dimensão e uma complexidade que obrigou a uma reescrita da história, o que simultaneamente contribuiu para que as histórias de muitas outras guerras que então se seguiram começassem a produzir um outro olhar, dentro dos vários olhares sobre as guerras.

$\mathrm{Na}$ nossa história muito recente, o papel da mulher na guerra tem vindo a ser alvo de discussão não só pela sua entrada no campo de batalha, difun-

cado em The Lancet, a 2 de Fevereiro de 1918, e Conflict and Dream (1923), entre outros textos. Ver também Showalter, 1987a. Sobre doenças do foro psicológico atribuidas às mulheres e que no pós-guerra serviram para compreender o drama do "shell shock", ver Showalter, 1987 b.

7 Cf. como a problemática se mantém em guerras mais recentes em Meintjes et al., 2001. 
dida para uma audiência global, como aconteceu na Guerra do Golfo de 1991, como também enquanto primeira vítima e primeiro alvo de massacres, como aconteceu no Ruanda, Burundi, Argélia e na antiga Jugoslávia, também divulgado à escala planetária (Goldstein, 2001: 1-2). Contudo, talvez este seja ainda um dos campos privilegiados para a afirmação do masculinismo (se me é permitido o neologismo) como ideologia de dominação e de superioridade e do feminismo como ideologia de promoção da igualdade. Esta é, grosseiramente, a base da discussão que reivindica para a mulher um lugar nas Forças Armadas e que simultaneamente a rejeita. ${ }^{8}$

$\mathrm{Na}$ nossa Guerra Colonial não foi esta a lógica que esteve na base dos papéis dos dois sexos na guerra. Clássica, neste sentido, a nossa guerra foi ainda terreno de afirmação dos ideais masculinos de guerra com a sua componente de crença na defesa da integridade da pátria e nos ideais guerreiros como parte essencial da formação da masculinidade e mesmo de uma espécie de teste de masculinidade com a "ida à tropa", vulgarizada na expressão popular: "a tropa fará de ti um homem". Desta forma, o papel masculino dependia dos papéis femininos no sistema de guerra, que incluíam as situações de esposas, namoradas, irmãs e, principalmente de mães, simbolicamente ligadas à imagem de casa (Vakil, 1999: 129) e historicamente ligadas a uma lógica de paz, ${ }^{9}$ na conhecida imagem da mater dolorosa, transposta por Fernando Pessoa para o menino de sua mãe que jaz morto e arrefece e que, nos anos da Guerra Colonial, inspirou a escultora Clara Menéres. Assim, a guerra era a destruição das tarefas do feminino tradicionalmente ligadas à maternidade e à manutenção do lar, mas era também e, paradoxalmente, feita para sua defesa, na comum asserção que permeia o discurso tradicional de todas as guerras e que as justifica pela defesa das "mulheres e crianças", ou seja, do status quo que elas teoricamente representariam. Mas são delas - mães, irmãs, mulheres, namoradas - os rostos crispados pela dor nas despedidas do cais do embarque, são delas os rostos de alegria e alívio no cais da chegada, são delas as horas de aflição com os filhos na mira de uma possível viagem para África para reencontrar o marido, são delas as rezas e as promessas nas peregrinações ao Santuário de Fátima, são delas os rostos absortos e magoados nas cerimónias das comemorações do dia de Portugal, onde lhes era entregue uma condecoração a título póstumo, atribuída àqueles que elas esperavam, e não chegaram.

\footnotetext{
${ }^{8}$ Sobre esta discussão, cf. Lorentzen e Turpin, 1998: 119-154, e os seguintes estudos recentes: Nação e Defesa, 88, 2 série, Inverno 1999 (número temático "A Mulher e as Forças Armadas"); Goldstein, 2001; Browne, 2001; e Carreiras, 2002.

${ }_{9}$ Para o desenvolvimento desta ideia, cf. Ruddick, 1990.
} 
12 | Margarida Calafate Ribeiro

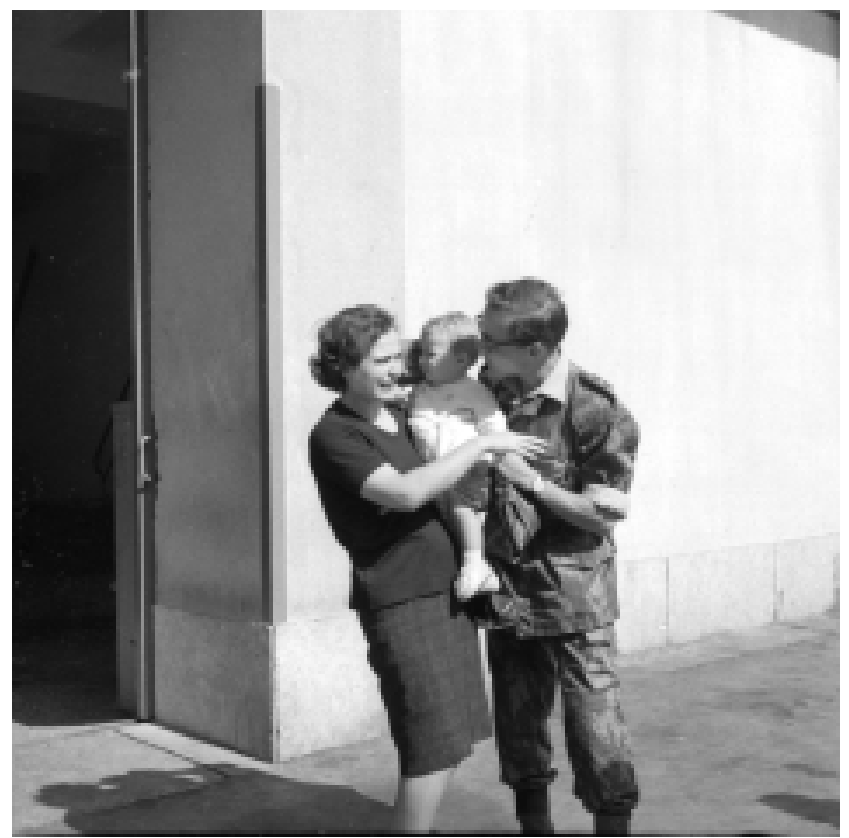

Partida de um contingente de tropas para Moçambique a bordo do paquete "Pátria", 10/10/1963

Fonte: O Século, Arquivo de Fotografia de Lisboa - CPF/MC; SNI/RP/03-66o6/54146

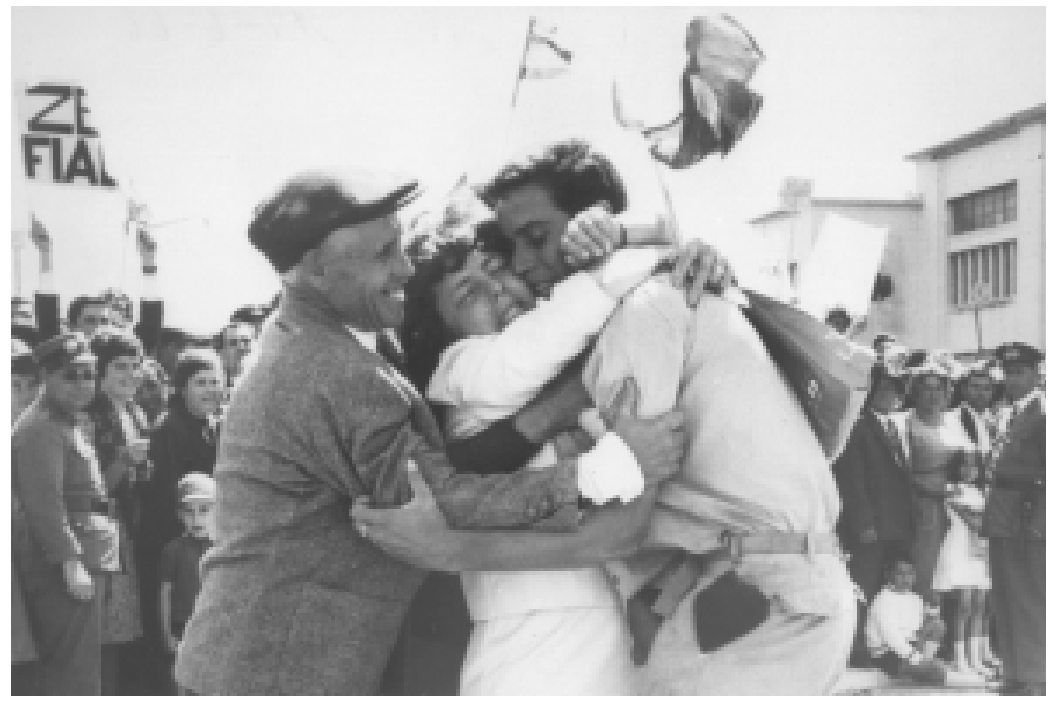

Regresso de militares do Ultramar, 6/1962

Fonte: O Século, Arquivo de Fotografia de Lisboa - CPF/MC; SNI/RP/03-66o6/54146 


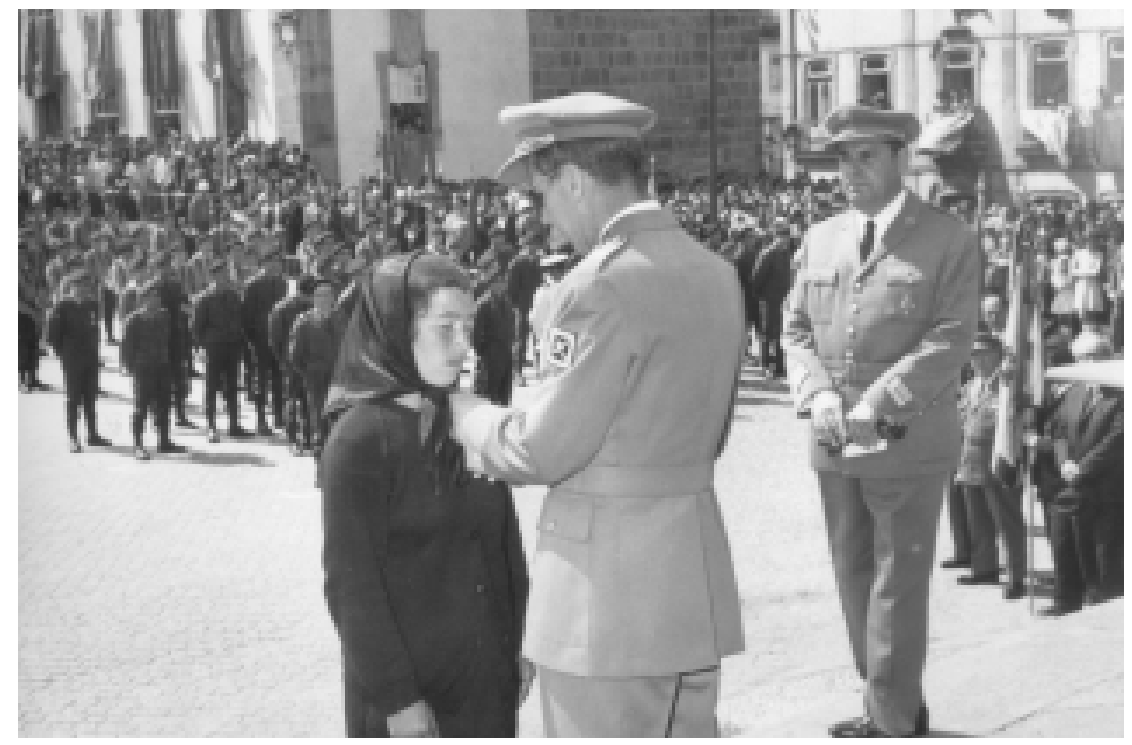

Condecoração de uma viúva, cujo marido foi galardoado a título póstumo

Fonte: Revista Flama, Arquivo de Fotografia de Lisboa - CPF/MC; SNI/RP/03-6506/14418

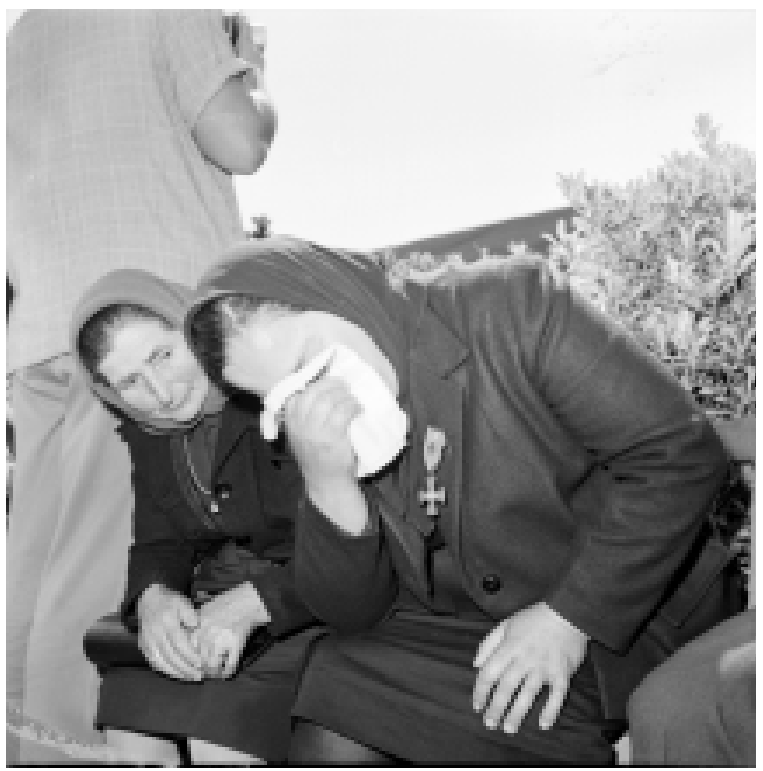

A mãe do $1 .{ }^{\circ}$ Cabo António Vitor Praxedes com a Cruz de Guerra da $4 .{ }^{a}$ classe, $10 / 6 / 1967$

Fonte: O Século, Arquivo de Fotografia de Lisboa - CPF/MC; SEC/AG/01-176/1558AS 
$\mathrm{Na}$ sociedade portuguesa, as ocupações da mulher directamente relacionadas com a guerra ligavam-se a tarefas de apoio. Desde a Primeira Guerra que elas se organizavam em associações, cuja função poderia resumir-se numa palavra - "assistir". "Assistir, educar e angariar fundos", mas também "assistir ao embarque dos soldados, assistir aos feridos, assistir as famílias dos mobilizados, assistir na medida do possível aos que ficavam dramaticamente presos nas fronteiras da Alemanha" (apud Viegas, 1989: 81), como fizeram as mulheres portuguesas ligadas à "Cruzada da Mulher Portuguesa" e à "Assistência das Portuguesas às Vítimas de Guerra", ambas surgidas na sequência da proclamação do estado de guerra em Março de 1916. ${ }^{10}$ Foi destas últimas a criação das "Madrinhas de Guerra", em Abril de 1917, que, quarenta e tal anos mais tarde, foram populares junto dos soldados na Guerra Colonial. A secção feminina da Cruz Vermelha, presidida por Amélia Pitta e Cunha, e o Movimento Nacional Feminino, liderado por Cecília Supico Pinto e criado na sequência do rebentamento da guerra em Angola, em 1961, têm nestas instituções da Primeira República as suas raízes de base de apoio aos militares, embora se distanciem da ideologia feminista que animava as mulheres da "Cruzada Portuguesa". Mesmo a ida de mulheres para o espaço de guerra, como aconteceu com as enfermeiras que acompanharam Corpo Expedicionário Português (CEP) na Primeira Guerra Mundial, ou o caso das enfermeiras pára-quedistas da Força Aérea, ${ }^{11}$ na Guerra Colonial, obedecia a esta lógica de apoio reservada às mulheres. No entanto, estas são as primeiras mulheres portuguesas a ir à frente de combate no ingrato trabalho de assistir e recolher feridos, e as suas experiências, algumas com mais de dez anos de África, nas três frentes de batalha, constituem testemunhos importantíssimos e únicos sobre a frente de combate, as relações entre homens e mulheres nas Forças Armadas e a sua relação com as populações.

Mas esta era, como referi, uma situação de excepção. A manutenção do mito de que a guerra é tarefa de homens possibilitava uma certa estabilidade social, cara ao regime que promovia a guerra. O estímulo que era esperado das mulheres era o de apoiar a guerra e, com ela, a ida dos homens, maridos ou filhos, para África e o seu bem-estar lá. No entanto, em Portugal não assistimos a campanhas de propaganda como vimos, por exemplo em Inglaterra, na Segunda Guerra Mundial. Oficialmente, não estávamos

\footnotetext{
${ }^{10}$ A "Cruzada da Mulher Portuguesa" era liderada pelas mulheres da nova elite política republicana e estava ideologicamente marcada pelos ideais feministas de então; por seu turno à "Assistência das Portuguesas às Vítimas de Guerra” ligavam-se nomes da recém deposta monarquia (Pimenta, 1989: 82-83).

${ }^{11}$ Sobre o assunto cf. Alves, 1999: 75-76; Ferreira, 1986.
} 
em guerra, mas nas publicações do Movimento Nacional Feminino, Presença e Guerrilha, ${ }^{12}$ eram feitos apelos às mães portuguesas para que sacrificassem os seus filhos "pela Nação" (apud Pimentel, 1996: 639) e nos jornais da época eram aplaudidas as mulheres que tinham muitos filhos e que os "davam" para a defesa do Ultramar português, numa atitude que relembra a propaganda de guerra tradicional que liga maternidade, nacionalismo e militarismo. Contudo, um movimento porventura inédito nesta guerra e pouco documentado nestes embarques foi o da ida de mulheres acompanhando os maridos em missão militar em África. Aproximando assim a chamada "frente interna" da frente de guerra, proporcionou-se uma certa estabilidade social dentro de um quadro de inevitável mudança. Paradoxalmente, criaram-se também, a prazo, as condições para a mudança, na medida em que essas mulheres seriam também testemunhas e, de alguma forma, cúmplices de um mundo de guerra, aparentemente reservado aos homens.

Lídia Jorge, escritora que registou ficcionalmente esta experiência feminina da Guerra Colonial em A Costa dos Murmúrios, refere numa entrevista que, quando chegou à Beira, em Moçambique, um militar fez a seguinte observação: "Só os Cartagineses levavam as mulheres para a guerra - e agora, os Portugueses." (Pedrosa, 1988: 10). A questão imediata seria: por que razão esta situação de excepção das mulheres portuguesas revelada na provocadora afirmação do militar?

Após o 25 de Abril de 1974, falou-se das mulheres que partiram com os maridos na ficção escrita por mulheres que tem por pano de fundo a Guerra Colonial e na crítica que subsequentemente tem vindo a ler estes livros. Mas antes do 25 de Abril, apenas nas publicações do Movimento Nacional Feminino, Presença e Guerrilha, se proclamava a "missão muito certa" das mulheres-esposas que acompanhavam os maridos vivendo "dois anos em África” com a missão de "valorizar a mulher negra” (apud Pimentel, 1996: 639).

Cabe perguntar: seria esta ida das mulheres para África, em acompanhamento dos seus maridos na guerra, parte de uma política traçada nos termos tradicionais, corporativos e ideológicos do regime ao combinar a missão familiar (acompanhar o marido, na retórica da política de família do Estado Novo) com a missão civilizadora ("valorizar a mulher negra")? Qual seria de facto o papel destas mulheres? Pensar-se-ia em colonizar com pessoas que, por definição, estavam numa situação transitória como são as comissões de serviço em tempo de guerra?

12 Presença, Revista do Movimento Nacional Feminino, publicação mensal dirigida por Luíza Manoel de Vilhena, e Guerrilha, revista mensal, dirigida por Cecília Supico Pinto e tendo como chefe de redacção, primeiro, Martinho Simões e depois, Mário Matos Lemos. 
Relembre-se que, ao mesmo tempo que decorria a Guerra Colonial, o regime estimulava a ida de famílias para colonizar as terras africanas, oferecendo passagens, concedendo empréstimos para explorações agrícolas através das Juntas Provinciais de Povoamento e outras facilidades.

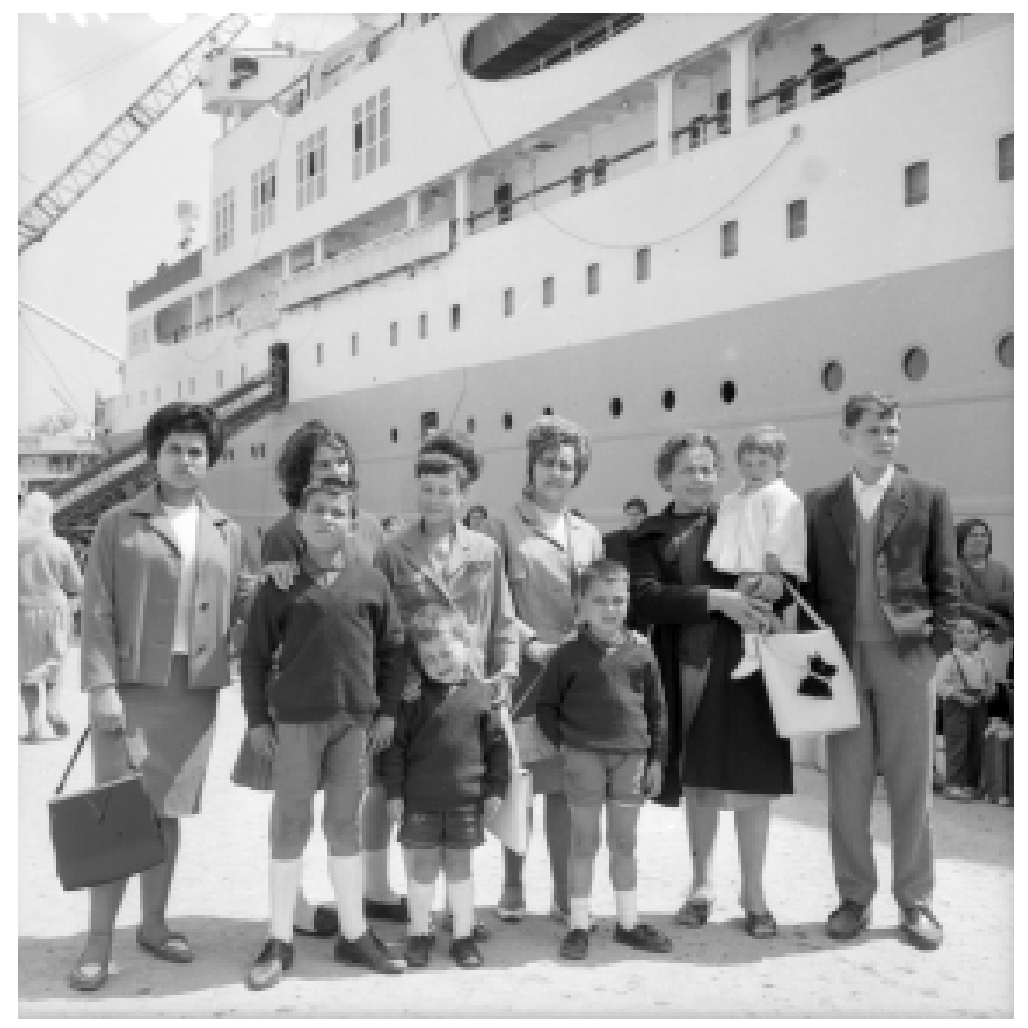

Partida de uma família de colonos para Angola a bordo do paquete "Vera Cruz" Fonte: O Século, Arquivo de Fotografia de Lisboa - CPF/MC; SEC/AG/01-170/1142AR

Nos jornais da época e na revista Permanência - publicada pela Agência Geral do Ultramar, dedicada ao "Portugal além-mar" e cujo nome não nos deixa dúvidas sobre as intenções da publicação - é dada notícia deste movimento, estimulado pelo regime através de uma legislação que apontava o Ultramar como o destino de emigração dos portugueses europeus, assim tentando contrariar o fluxo migratório para a Europa, que ia minando a opção ultramarina. Por seu turno, nas revistas do Movimento Nacional Feminino, são vários os textos que defendem, na linha do regime, a presença portuguesa em África, fazendo apelo a um acompanhamento da acção militar 
por uma política rápida e sólida de colonização. ${ }^{13} \mathrm{E}$ nesta altura não se estava seguramente a falar de uma colonização masculina, mas antes de famílias de portugueses europeus pois, como dizia Maria Archer, referindo-se à falha da colonização portuguesa em África, "uma civilização só se fixa e define através da mulher" (Archer, 1963: 166). Ora, se na ordem estado-novista "a família é a fonte de conservação e desenvolvimento da raça" e o "fundamento de toda a ordem política" (apud Cova e Pinto, 1997: 73) e se se ia para a guerra defender a ordem política da nação, ou seja, evitar a fragmentação do corpo/família nacional de que a guerra movida pelos africanos era expressão e desejo, então era natural que se fosse para a guerra em família, a célula unida de controlo moral e político, ${ }^{14}$ contra os "inimigos do exterior", capaz de regenerar o conjunto do corpo nacional. Que melhor maneira poderia haver para impor/proteger/regenerar (a partir da estrutura mínima da nação portuguesa, a "sagrada família portuguesa") a ordem vigente?

É certo que esta ida das mulheres para África proporcionou uma maior estabilidade aos portugueses europeus deslocados na guerra, que assim partilhavam com as famílias o dia-a-dia, e deu a uma classe jovem a vivência de África, não como um lugar distante onde se vai para a guerra, mas como um lugar onde se vive em família, nascem filhos, se formam crianças portuguesas, se convive com os amigos, se comemoram os dias nacionais e onde brotavam oportunidades de trabalho que não havia na metrópole, pois a guerra, para o bem ou para o mal, também acelera a economia, animando assim as pessoas a ir ficando ou, por outras palavras, a ir colonizando/emigrando/fazendo a guerra, como um gesto inconfessado enquanto tal.

No entanto, a análise da legislação da época relativa aos apoios por parte do Estado à deslocação e manutenção de militares não nos leva a concluir

\footnotetext{
${ }^{13}$ Cf., por exemplo, o seguinte texto de Pedro Cabrita: “[...] que se faz para além do esforço militar para permanecermos Lá? Na resposta a esta pergunta encerra-se o julgamento futuro que a Nação vai fazer aos governantes de hoje. E, se eles não envidarem todos os esforços no único sentido válido, mal vai a Nação, pior irá a Pátria. E o único sentido válido sai desta verdade: se em quatro ou cinco anos não forem qualificados na Metrópole (e qualificados técnica, cultural e politicamente) centenas de milhares de portugueses metropolitanos capazes de irem para Angola e Moçambique e se não forem colocadas essas centenas de milhares de portugueses no Ultramar, Portugal sairá de África.

A opção do Governo, portanto, só pode ser uma: criar condições através da acção de todos os Ministérios (desde o mais político ao menos político) para que seja possível colocar em Angola e Moçambique, no mais curto espaço de tempo, centenas de milhares de portugueses metropolitanos. [...] A grandeza da ideia ultramarina - e essa é a ideia de Portugal - exige colada a esse sacrifício [dos jovens militares] toda uma enorme tarefa de povoamento, de progresso económico, cultural e social." (Cabrita, 1964: 5).

${ }^{14}$ Sobre o valor terapêutico da família na ordem salazarista, ver o interessante estudo de Moisés de Lemos Martins (1986: 77-83).
} 
18 | Margarida Calafate Ribeiro

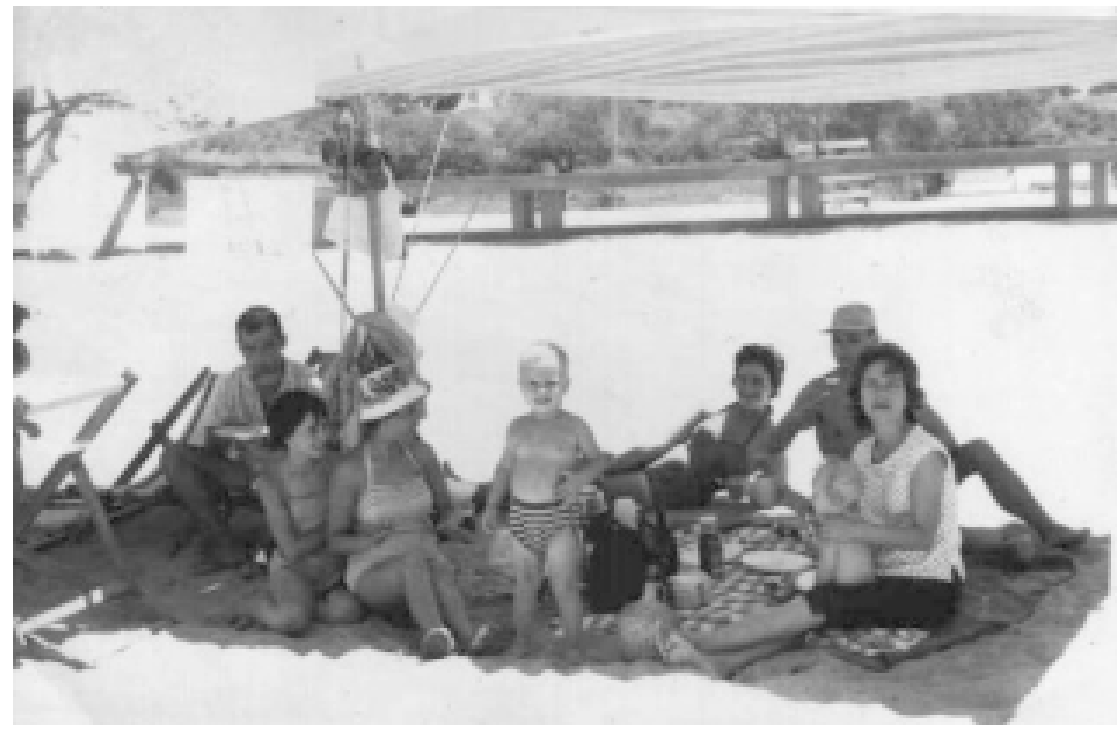

Aspectos da vida familiar, Moçambique, 1968

Fonte: Rosa Nogueira

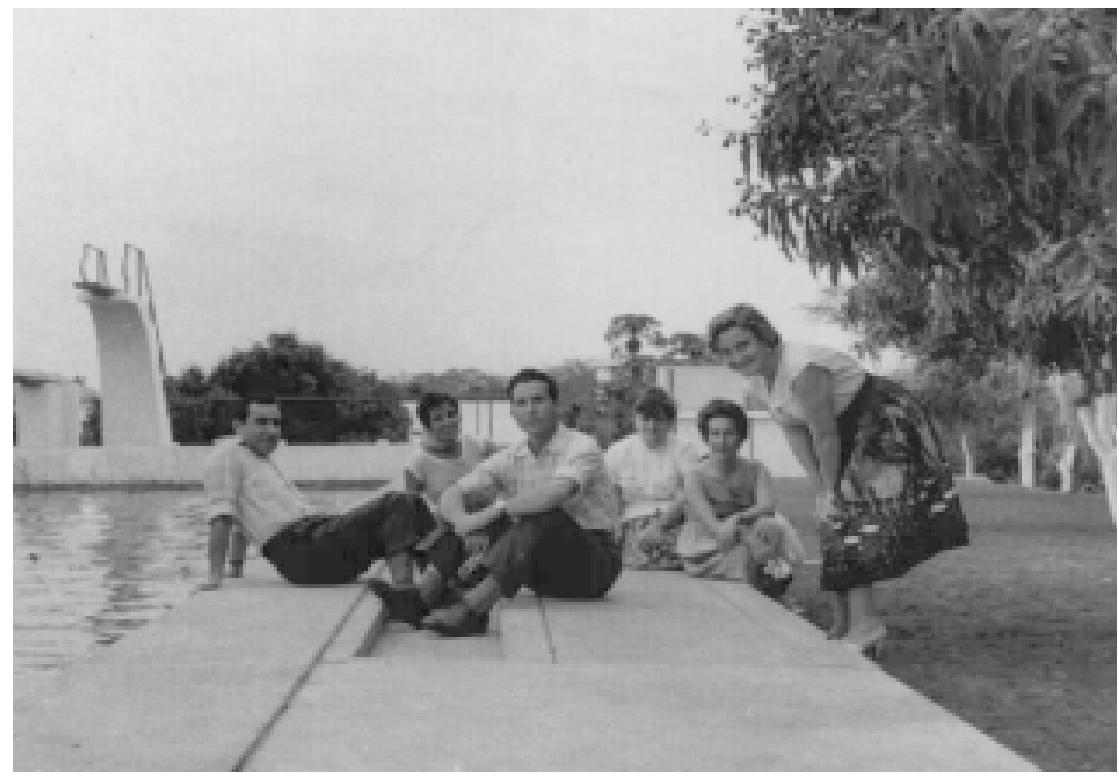

Convívio com amigos, Moçambique, 1969

Fonte: Rosa Nogueira 
que houvesse uma política previamente pensada, ainda que houvesse certas facilidades e um estímulo de difícil interpretação. Houve antes uma política de apoios que era consequência da longevidade da guerra. Assim, a lei de transportes que vigorava à data do início da guerra em Angola datava de 1931, referindo-se, portanto, a um tempo de paz. Seguiram-se vários despachos, que adaptavam esta lei às condições de guerra, estabelecendo as normas para a execução de transportes, e logo em 1962 é referido o transporte de famílias de militares. Mais tarde, em 1964, normalizava-se o transporte das famílias indicando os requerimentos a fazer pelos militares para obter estas viagens, a hierarquização de competências e responsabilidades relativamente ao transporte, as condições impostas e o processamento de embarque, tornando assim mais assumido o exercício deste direito por parte dos militares. No entanto, só em Junho de 1969, quando eram já visíveis os sinais de cansaço da guerra e se tornava necessário aliciar os militares em permanentes comissões de serviço em África, é que, através do decreto-lei 49107 (artigo 21. ${ }^{\circ}$ ), se estabelecem as várias situações relativas às famílias de militares no relativo a direitos e deveres. De acordo com o documento, todo o pessoal nomeado por oferecimento ou por escolha, além dos direitos em vigor, tinha também direito a: transporte da família por conta do Estado para a "província ultramarina" e de regresso para a nova colocação do militar; tratamento médico por conta do Estado; assistência médica e medicamentosa para as famílias durante o período da comissão; alojamento por conta do Estado na localidade da guarnição ou subsídio de renda de casa. Aqueles que tivessem sido nomeados por imposição poderiam gozar dos mesmo direitos, caso já tivessem efectuado uma comissão de serviço, por imposição ou por escolha, posterior a Janeiro de 1961. Em 19 de Agosto de 1969, nas normas executoras do referido decreto-lei, eram definidas outras directivas importantes, nomeadamente a exigência de que a família do militar a viajar por conta do Estado permanecesse em território ultramarino por um tempo minímo de doze meses, salvo casos especiais. Consultando o arquivo do Depósito Geral de Adidos, a instituição militar que tratava da logística de todo o tipo de viagens entre Portugal e os vários territórios ultramarinos, encontramos inúmeros processos de militares solicitando viagens por conta do Estado para as suas famílias, listas de famílias a embarcar e que embarcaram, correspondência entre o serviço do Depósito Geral de Adidos e as famílias dos militares.

Observando as listas de famílias a embarcar, verificamos que eram poucas as mulheres que viajavam sozinhas. A grande maioria viajava com filhos pequenos: são vários os casos de crianças de meses (uma de dezanove dias) e raramente ultrapassam os dez anos, indicando-nos assim que se tratava de 
jovens casais. As origens geográficas destas famílias cobrem todo o território português continental e ilhas adjacentes. As origens sociais, que inferimos pelo posto do militar, são também as mais diversas, o que determinava uma certa hierarquização relativamente ao meio para viajar. Assim, por exemplo, as mulheres de oficiais viajavam de barco em 1. ${ }^{a}$ classe ou de avião na chamada posição "excedentária", sobretudo a partir de 1967, altura em que a Força Aérea começa a assegurar grande parte dos transportes, enquanto, por exemplo, as mulheres de sargentos viajavam de barco em 2. ${ }^{a}$ classe e, no caso de quererem viajar de avião, tinham de pagar a diferença. Os destinos destas famílias são os esperados: Bissau, na Guiné; Luanda, Carmona, Luso, Sanza Pombo, entre outros, em Angola; Lourenço Marques, Beira, Quelimane, Macimboa da Praia, Nampula, em Moçambique. A maioria das mulheres e famílias ficava nas cidades, mas houve algumas que viveram no mato, em casas próprias em pequenas povoações adstritas aos quartéis ou na própria área dos quartéis, dependendo da autorização dos comandantes. Quanto às condições de instalação, as situações são extremamente diversas e resultam mais de adaptações ao que já existia e outros ajustes e conveniências do que de um planeamento previamente delineado.

Um outro aspecto importante destas listas é a indicação de um elevado número de desistências ou a indicação de "viajou por conta própria", tornando assim impossível seguir as famílias até aos seus destinos. Os motivos das desistências, explicados na correspondência enviada pelas interessadas ao comandante da Direcção Geral de Adidos prendem-se com vários aspectos, entre os quais: à data da viagem o militar encontrava-se numa zona onde já não era possível estar com a família; a família tinha sido avisada da data de embarque muito em cima da hora, sem possibilidade sequer de cumprir o prazo de dez dias para tomar as vacinas necessárias antes do embarque; o ano escolar tinha-se iniciado e os filhos estavam a estudar, não sendo portanto conveniente a sua deslocação; nascimento de um bebé, as doenças das crianças, etc. De acordo com a legislação, a família deveria ser avisada pelo menos com trinta dias de antecedência, mas isso raramente acontecia, como podemos inferir da correspondência. Também na correspondência que solicita informações sobre a viagem são frequentemente evocados motivos domésticos ou ligados à educação dos filhos para solicitar as viagens em determinados períodos. No entanto, encontramos também algumas mulheres que eram professoras e solicitavam uma ida antes do início do período escolar no Ultramar, deixando-nos assim antever que iam trabalhar. Outras, normalmente casadas com oficiais de patentes mais elevadas, solicitavam a viagem para uma serviçal, como então se dizia, para as auxiliarem na educação dos filhos, numa terra "de hábitos tão diferentes". 
Mas é também nos casos de patentes mais elevadas que há mais desistências. As mulheres que normalmente não desistiam eram mulheres de cabos, furriéis, sargentos e até de soldados, estas raras, muito raras. Apesar de esta legislação se destinar, em princípio, a militares do quadro, há também indicação de que seguiram viagem por conta do Estado algumas (muito poucas no geral) mulheres ou famílias de oficiais milicianos. Falando com pilotos da Força Aérea Portuguesa de então, hoje já na reforma, estes recordam a aventura do transporte dessas famílias nos aviões, cheios de tropas, correio e carga e certamente desconfortáveis para quem viajava com crianças ao longo de tantas horas, com diversas escalas e por rotas nem sempre directas, pois a Força Aérea Portuguesa estava impedida de sobrevoar grande parte da África subsariana. Mesmo outros militares, quando confrontados com a questão da importância da presença das suas mulheres durante a guerra, reconhecem-lhes um papel fundamental na manutenção de uma certa aura de normalidade familiar num teatro de guerra. Alguns reconhecem-lhes também um importante papel no exterior da casa portuguesa que elas transpuseram para África, nomeadamente na acção social e no ensino. Muitas das mulheres que viveram em África apenas acompanharam os maridos, e "as suas guerras" eram os partos, a amamentação, os filhos, mas muitas trabalharam no apoio das populações, normalmente ligadas a missões religiosas, prestaram cuidados médicos e de enfermagem, foram professoras em vários níveis de ensino, fizeram trabalho de secretariado nos serviços das próprias Forças Armadas ou em empresas.

O registo destes passos consta dos registos biográficos profissionais de cada uma, mas no Arquivo do Ministério da Educação podemos verificar que a sua contribuição foi fundamental para um considerável incremento da educação, com a criação de muitas escolas primárias, liceus, institutos e, finalmente, dos Estudos Gerais que viriam a ser, dois anos mais tarde, as universidades de Luanda e de Lourenço Marques. Ao longo dos anos 60, e sobretudo comparando com a década anterior, é significativa a numerosa legislação conjunta do Ministério da Educação e do Ministério do Ultramar, que visava, por um lado, dotar as colónias portuguesas de muito mais estabelecimentos de ensino, nos vários níveis, e, por outro lado, uniformizar o mais possível todas as situações com a então metrópole. Assim, e à semelhança do que acontecia noutros sectores da vida nacional, desde as Finanças à Saúde, ao nacional-cançonetismo, ao futebol, à tourada, a Fátima ou às misses de Portugal, a palavra de ordem parecia ser "integração" e uniformização. De alguma forma, as mulheres ao "completarem" a moldura como lhes era requerido, terão contribuido para a manutenção de uma certa estabilidade, não só porque com a sua ida mantiveram a célula 


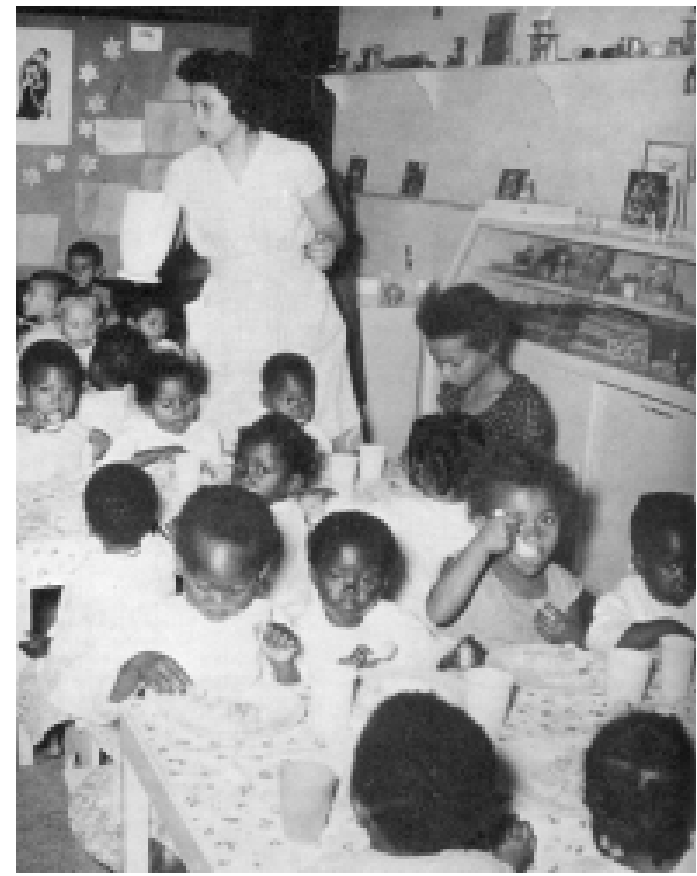

Professora num jardim de infância

Fonte: Revista Permanência

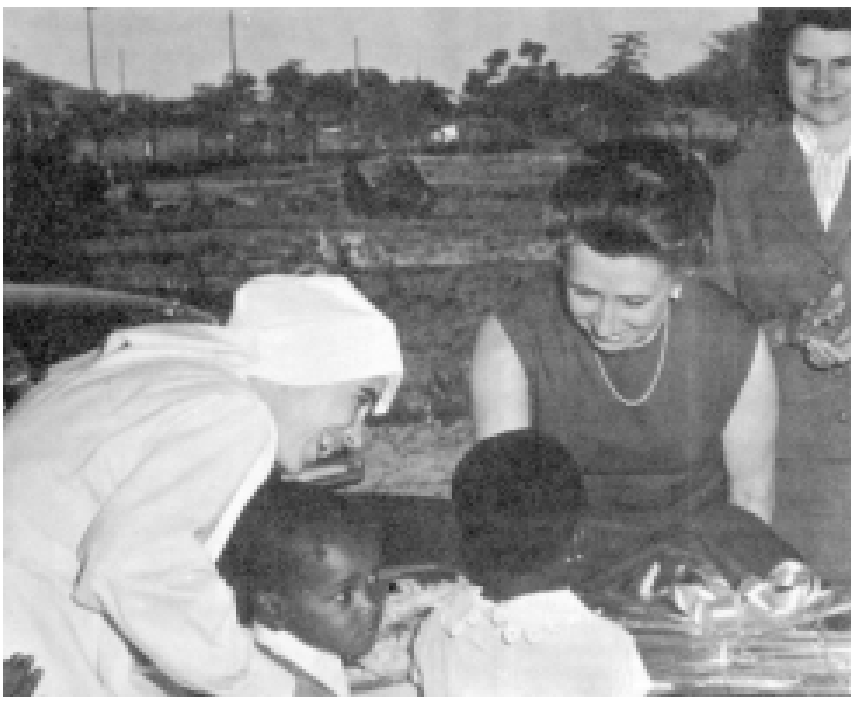

Senhoras na acção social junto de missões religiosas

Fonte: Revista Permanência 
familiar junta - o que nem sempre significou unida -, como também pela contribuição social que prestaram. Acredito que muitas das mulheres que foram para África, acompanhando os maridos na guerra, colaboraram, voluntária ou involuntariamente, consciente ou inconscientemente, para a produção do disfarce da guerra sob uma imagem de normalidade que o regime queria projectar. No entanto, e como é bem visível nos depoimentos que podemos obter destas mulheres e na literatura que ficcionalmente as refere, ${ }^{15}$ havia outras mulheres portuguesas que parecia não encaixarem na moldura requerida e esperada. ${ }^{16}$ Para muitas destas mulheres, aliás à semelhança dos homens, a vivência em África foi o momento de encontro com "a realidade que era [...] o nosso império", a percepção do que significava "um grande território para um pequenino país colonizador" e sobretudo o desvendar do "logro enorme" que sobre tudo isto se tecia e que levaria à inevitável e irreversível ruptura. ${ }^{17}$ Lídia Jorge, que viveu em África nos anos 60/70 e é autora de $A$ Costa dos Murmúrios, define numa entrevista o impacto da realidade da Guerra Colonial e da sociedade que a envolvia como um "esmagamento" (Letria e Serrano, 1998: 11), atestando na violência intrínseca à palavra escolhida a crise de identidade pessoal, familiar e nacional que ela, como algumas outras, terão experienciado. Falando hoje com estas mulheres, elas recordam este tempo com a doçura com que todos nós recordamos a juventude, os primeiros anos de casamento, os filhos pequenos, mas também os casamentos apressados por causa da guerra, a angústia das missões dos maridos, os voos dos helicópteros e aviões que traziam os feridos, os boatos que alimentavam a guerra. Os testemunhos que delas podemos recolher levam-nos a pensar sobre quanto a guerra terá alterado o mito dos brandos costumes, os seus comportamentos sexuais e, apoiando-me nas palavras de Manuel Alegre, na consequente importância social e

\footnotetext{
15 Em A Costa dos Murmúrios, de Lídia Jorge, Evita e Helena de Tróia dominam o cenário que tem na retaguarda outras mulheres, cujas identidades ora se definem em conjunto - as "mulheres do Stella" (p. 119) as "raparigas de cabelo passado a ferro", "mulheres dos vestidos sem costas", "raparigas de cabelo comprido" ou "de cabelo em forma de colmeia" (p. 116), "uma moldura de mulheres que habitam o Stella" (p. 232) - ora em relação ao marido, incorporando o seu nome ou a sua categoria militar - a mulher do Ladeira, do Zurique, do Góis, do major, "a mulher do Astorga", "a mulher do Fonseca" (p. 109), "a mulher do capitão Pedro Deus" (p. 110), "a mulher dum capitão piloto-aviador" (p. 19), "uma mulher de alferes" (p. 21). Todas estas mulheres, descritas de forma pouco elogiosa e irónica pela narradora viviam no Stella Maris mais preocupadas com as promoções e oportunidades de ascensão social e de riqueza que a guerra trazia do que com os perigos que os maridos corriam. "As mulheres do terraço [...] ouvindo o piloto [...] sabiam que estavam em fila, esperando que os seus homens desempenhassem um papel histórico” (p. 114), diz-se também em A Costa dos Murmúrios.

${ }_{16}$ Veja-se as protagonistas de A Costa dos Murmúrios, de Lídia Jorge, e de Percursos - do Luachimo ao Luena, de Wanda Ramos.

17 Citações retiradas da entrevista de Inês Pedrosa a Lídia Jorge (Pedrosa, 1988: 10).
} 
política do acto das jovens mulheres da época que "entregavam a virgindade sem cálculo nem resistência" num "acto de rebelião e cumplicidade que profundamente subvertia tudo" (Alegre, 1989: 70). A guerra alterou as relações entre os dois sexos de forma significativa, no domínio público, ao deixar as mulheres entrar para o mercado de trabalho com uma segurança nunca antes conhecida, e no domínio privado, ao quebrar tabus e transformar as relações entre namorados, entre marido e mulher.

As mulheres que tenho vindo a entrevistar no âmbito de um trabalho de registo da experiência das mulheres portuguesas em África em acompanhamento dos seus maridos, quando questionadas sobre as suas motivações para ir para África em plena Guerra Colonial, repetidamente repetem a minha pergunta na primeira pessoa - porque é que fui, porque é que fomos nós mulheres? - acabando por responder. As motivações para a ida são assumidamente privadas, mas muitas hoje apontam a habilidade política do regime em ter mantido estas opções como privadas e pessoais nunca as deixando transbordar para o domínio público e colectivo. Desta forma, e de acordo com a opinião de algumas das minhas entrevistadas (é importante sublinhar que não se trata de um julgamento colectivo), o regime comprometeu as mulheres com a guerra e sem se comprometer e sem grande esforço proporcionou uma situação de luta em duas frentes, mas também de grande normalidade. Como me dizem, "nós acolhíamos, humanizávamos e simplificávamos a vida". Saindo da esfera da vida privada, muitas reconhecem o incremento que a sua presença deu ao ensino local, atribuindo assim a esta experiência uma relevância pública, mas também privada, na medida em que este contacto lhes proporcionou uma visão-outra sobre as várias populações locais que na escola se juntavam. Colocadas na margem do universo da guerra, registaram esta experiência, ouviram, observaram, traçaram relações com o poder e foram revelando um olhar-outro, elaborando uma razão-outra, sobre as razões do conflito bélico que me parece interessante conhecer e registar.

No pós-guerra, foi mais uma vez sobre as mulheres que caiu a expectativa do regresso a uma certa normalidade.

Mas o pós-guerra da nossa Guerra Colonial não criou uma Ilha dos Amores como Camões poeticamente tinha previsto para regenerar os homens da violência que todas as guerras importam: muitos casais separaram-se no rescaldo da guerra, mas muitos mantiveram-se unidos, cúmplices desse tempo africano nem sempre fácil de contar aos filhos, outros foram lidando com situações complicadas, dramas psicológicos e desajustamentos que foram transformando para sempre as relações familiares, ao transferir a violência da guerra para o espaço doméstico. Antes do 25 de Abril, não se 


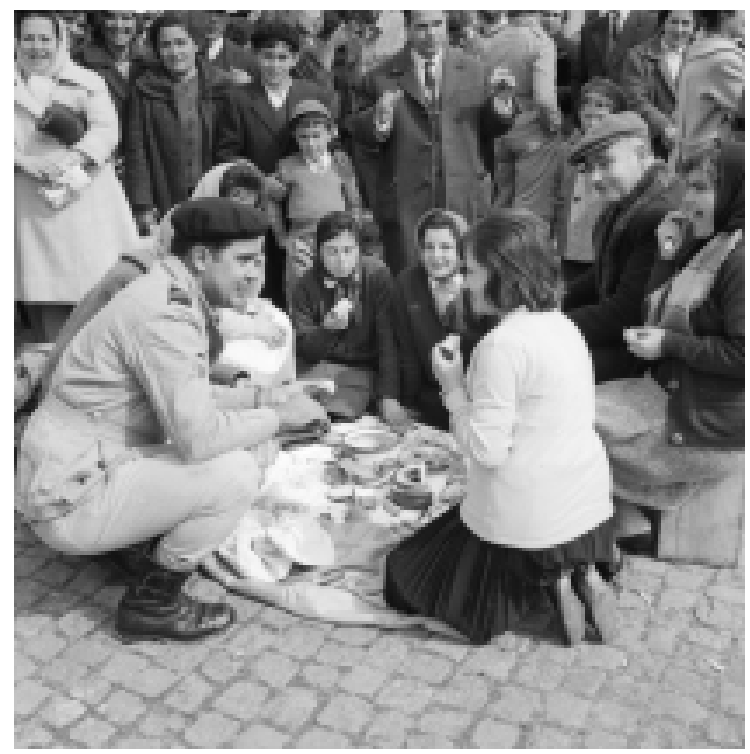

Acolhimento familiar a tropas regressadas de Angola a bordo do «Vera Cruz», 01/04/1964

Fonte: Arquivo de Fotografia de Lisboa - CPF/MC; SEC/AG/01-156/0532AP

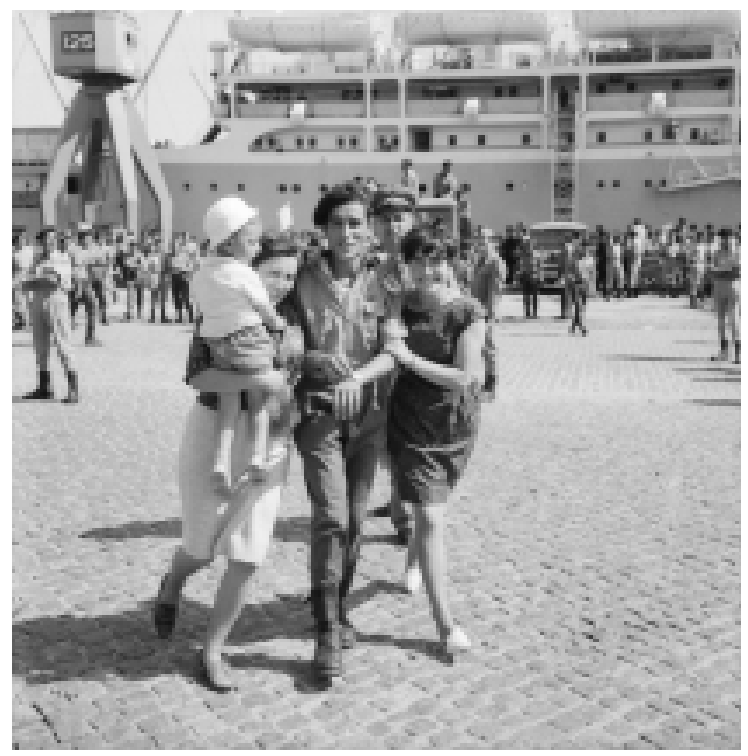

Regresso de um contingente de tropas do Ultramar a bordo do paquete «Uíge», 20/05/1966

Fonte: Arquivo de Fotografia de Lisboa - CPF/MC; SEC/AG/01-170/1142AR 
falava da guerra para que ela não existisse, como nos mostram os jornais em que as fotografias de embarques e desembarques desaparecem a partir de 1969. Em 1972, Marcello Caetano nas suas "Conversas em Família” dizia:

Guerra Colonial? As Províncias Ultramarinas estão em paz e ninguém neles contesta a sua integração na Nação Portuguesa. Percorre-se a Guiné, anda-se pela vastidão da terra angolana, desloca-se quem quer que seja de lés a lés de Moçambique e não encontra populações revoltadas. [...] A vida decorre, por toda a parte, tranquila e normal, num ambiente de trabalho e de entendimento exemplares. (Apud Carvalho, 1977: 108)

Depois do 25 de Abril, gritou-se "Nem mais um soldado para as colónias" e rapidamente se deixou de falar da guerra. No entanto, a ocultação da guerra, feita no pós-25 de Abril, não era um artíficio de vontade autoritária, mas antes uma incapacidade de avaliação das condições reais para lidar com tão dolorosa e explosiva herança, deixando o ex-combatente num ambíguo e desconfortável lugar entre a vítima "de uma engrenagem monstruosa" (Garcia, 1996: 108) e a imagem de um antigo poder que se queria esquecer. Assim, à ocultação da guerra feita pelo antigo regime, projectando um retrato de nada estar a acontecer, seguia-se a ocultação da guerra como se fosse possível fazê-la desacontecer, como se tudo tivesse sido um engano, ou, como aliás veio a dizer o próprio "inimigo", Samora Machel, um equívoco, uma história de mal-entendidos. Mas ela tinha de facto acontecido lá longe em África, como indicam os títulos de referências espaciais de Os Cus de Judas, de António Lobo Antunes ou Lugar de massacre, de José Martins Garcia. Todavia, a guerra não estava só em África, como o antigo regime pretendia, e onde parece que o novo regime, saído do 25 de Abril, gostaria de a ter deixado, desejando assim que ela não tivesse acontecido, mas ela vinha a bordo dos navios que regressavam ao cais. Por isso, o 25 de Abril não foi a libertação singularmente pacífica que todos rapidamente quiseram ler no encantamento da nossa jovem democracia. O 25 de Abril estava, desde o seu primeiro movimento, manchado pelo sangue derramado lá longe em África, como os barcos que durante anos cumpriram estas rotas entre Portugal e uma África em guerra de libertação. Mas o 25 de Abril foi antes de mais o fim da Guerra Colonial, como diz uma mãe de um soldado, no rescaldo de toda essa experiência de angústia e separação:

O melhor que o 25 de Abril trouxe para mim foi o fim da Guerra Colonial. [...] Nunca percebi porque é que os nossos filhos tinham de ir combater em terras que para mim nada tinham a ver connosco. 
Quando chegou a altura de o meu filho ser chamado só me apetecia dizer-lhe que fugisse, que não fosse. Mas nunca o fiz. Porque, por outro lado, sabia que se ele o fizesse talvez nunca mais o voltasse a ver pois não poderia pôr mais os pés em Portugal. [...] No entanto, quando ele estava em África sofrendo todos aqueles horrores, porque foram verdadeiros horrores com a morte sempre à frente dos olhos e fazendo os outros sofrer, cheguei a arrepender-me de nunca o ter encorajado a sair do País.

Logo depois do 25 de Abril, quando soube que os nossos filhos iam regressar até chorei de alegria! (Maria de Jesus, dona de casa, in Mulheres, 12 de Abril de 1979: 11)

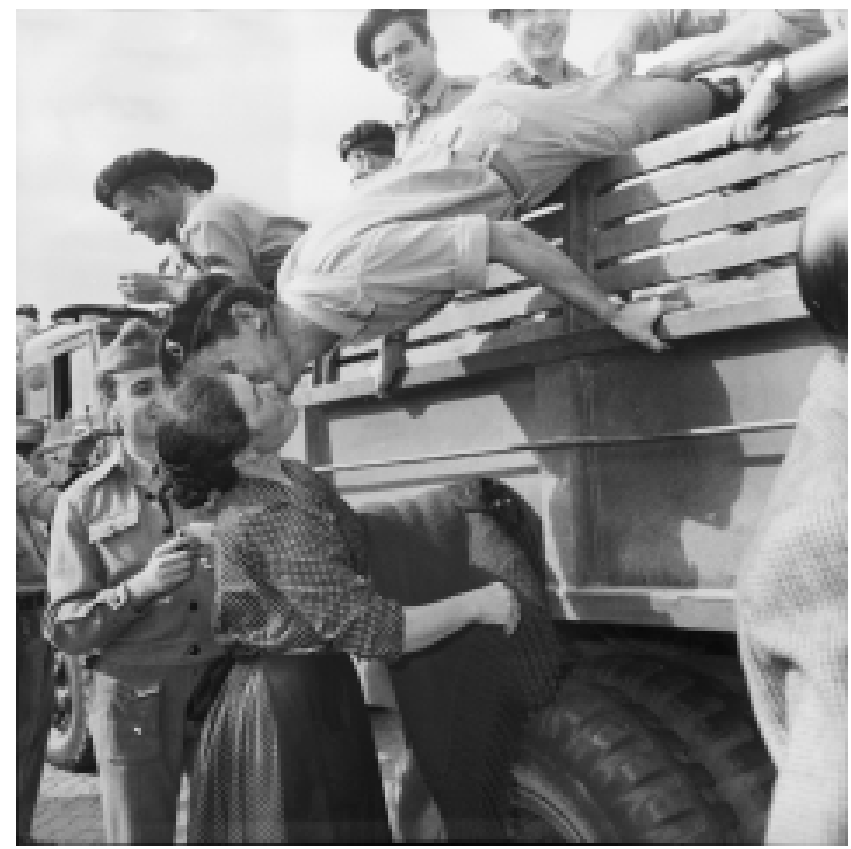

Regresso de tropas de Moçambique a bordo do paquete «Angola», 14/09/1962 Fonte: Arquivo de Fotografia de Lisboa - CPF/MC; SEC/AG/01-147/1524AN

Para quem ficou, África não teve feminino. A África era tão-só o local de onde ninguém queria falar e para onde silenciosamente embarcavam homens, que voltavam transformados. As mulheres que foram com eles ou as que os aguardavam no cais recebiam outros homens, que inevitavelmente as iriam transformar e transformar as relações privadas e públicas no contexto da sociedade portuguesa. Por isso, ver a guerra como uma actividade exclusivamente masculina é contar apenas uma parte da história. 


\section{Referências Bibliográficas}

Alegre, Manuel (1989), Jornada de África. Lisboa: Dom Quixote.

Alves, José Hermínio Estevão (1999), “A mulher e as Forças Armadas Portuguesas”, Nação e Defesa, $2^{a}$ série, 88, 71-88.

Antunes, José Freire (1995), A Guerra de África. Lisboa: Círculo de Leitores.

Archer, Maria (1963), Brasil: Fronteira da África. São Paulo: Editora Felman-Rego.

Bebiano, Rui (1993), “O espelho de Marte, ou guerra como imagem”, Revista de História das Ideias, 15, 75-116.

Brosman, Catherine Savage (1992), "The Functions of War Literature”, Journal of the South Central Modern Language Association, 9(2), 85-98.

Browne, Kingsley R. (2001), "Women at War: An Evolutionary Perspective”, Buffalo Law Review, 49(1).

Cabrita, Pedro (1964), "Razão de uma luta", Presença - Revista do Movimento Nacional Feminino, 3, 5 .

Camões, Luís de (1992), Os Lusíadas. Lisboa: Ministério da Educação/Instituto Camões.

Carreiras, Helena (2002), Mulheres em armas - a participação feminina na Europa do Sul. Lisboa: Edições Cosmos / Instituto de Defesa Nacional.

Cortesão, Jaime (1919), Memórias da Grande Guerra (1916-1919). Porto: Renascença Portuguesa.

Carvalho, Otelo Saraiva de (1977), Alvorada em Abril. Amadora: Bertrand.

Cova, Anne; Pinto, António Costa (1997), “O Salazarismo e as mulheres - uma abordagem comparativa”, Penélope, 17, 71-94.

Dias, Eduardo Mayone (1995), "Flandres e África: a visão de uma guerra distante”, in João Camilo dos Santos; Frederic G. Williams (orgs.), O amor das letras e das gentes - In honour Maria de Lourdes Belchior Pontes. Santa Bárbara: University of California, 425-446.

Ferreira, J. Diniz (1986), A mulher nos céus de Portugal. Lisboa: Edição do Autor.

Fussell, Paul (1975), The Great War and Modern Memory. Oxford: Oxford UP.

Garcia, José Martins (1996), Lugar de massacre, Lisboa: Edições Salamandra [11975].

Goldstein, Joshua S. (2001), War and Gender. Cambridge: Cambridge UP.

Higonnet, Margaret et al. (orgs.) (1987), Bebind the Lines - Gender and the Two World Wars. New Haven/London: Yale UP.

Jorge, Lídia (1988), A Costa dos Murmúrios. Lisboa: Círculo de Leitores.

Keegan, John (1985), The Face of the Battle: A Study of Agincourt, Waterloo and the Somme. London: Viking Penguin.

Letria, José Jorge; Serrano, Miguel (1988), “ A escrita é mesmo a minha vida”, O Diário - Fim de Semana, 5 Março, 11-12 (entrevista a Lídia Jorge).

Lorentzen, Lois Ann; Turpin, Jennifer (orgs.) (1998), The Women and War Reader. New York/London: New York UP. 
Macedo, Helder (1998), “Love and Knowledge: The Lyric Poetry of Camões”, Portuguese Studies, 14, 51-64.

Martins, Moisés de Lemos (1986), "Uma solidão necessária à ordem salazarista: a família como terapêutica nacional”, Cadernos de Ciências Sociais, 4, 77-83.

Meintjes, Sheila; Pillay, Anu; Turshen, Meredeth (orgs.) (2001), The Aftermath - Women in Post-Conflict Transformation. London/New York: Zed Books.

Monteiro, Renato; Farinha, Luís (org.) (1998), Guerra Colonial - Fotobiografia. Lisboa: Dom Quixote.

Owen, Wilfred (1983), The Complete Poems and Fragments (org. Jon Stallworthy). London: Chatto \& Windus, The Hogarth Press e Oxford UP.

Pedrosa, Inês (1988), "Este é um livro sobre a violência”, Ler, 1, 9-13 (entrevista a Lídia Jorge).

Pimenta, Maria Teresa Viegas (1989), “As mulheres portuguesas na Guerra de 1914/18”, Cadernos da Condição Feminina, 29, 81-86.

Pimentel, Irene Flunser (1996), “Movimento Nacional Feminino”, in Fernando Rosas; J. M. Brandão de Brito, Dicionário de História do Estado Novo, vol. 2. Lisboa: Círculo de Leitores, 639.

Ramos, Wanda (1981), Percursos - do Luachimo ao Luena, Lisboa: Presença.

Rivers, W. H. (1918), “The Repression of War Experience”, The Lancet, 2 Fevereiro (disponível em http://www.sassoonery.demon.co.uk/lancetpaper.htm).

Rivers, W. H. (1923), Conflict and Dream. London: Kegan Paul, Trench, Trubner \& Co.

Ruddick, Sara (1990), Maternal Thinking - Towards a Politics of Peace. London: The Women's Press.

Showalter, Elaine (1987a), "Rivers and Sassoon: The Inscription of Male Gender Anxietes", in M. Higonnet et al. (orgs.), Bebind the Lines - Gender and the Two World Wars. New Haven / London: Yale UP, 61-69.

Showalter, Elaine (1987b), The Female Malady - Women, Madness and English Culture, 1830-1980. London: Virago Press.

Valensi, Lucette (1996), Fábulas da memória - a gloriosa batalba dos três reis. Porto: Edições Asa.

Vakil, Abdoolkarim (1999), "At War with the Nation: Patriotism and the Gendered Discourse of Citizenship in WWI Portugal“, Ellipsis - Journal of the American Portuguese Studies Association, 1, 122-142. 